\title{
Gestão de práticas esportivas escolares no ensino fundamental no município de Santos
}

CDD. 20.ed. 796.05

\section{Resumo}

A presente pesquisa teve por objetivo analisar as condições das práticas esportivas escolares (PEEs) no ensino fundamental no município de Santos - SP sob o ponto de vista dos gestores escolares, com relação à: a) percentual de atendimento no âmbito público; b) descrição dos recursos materiais e financeiros; c) caracterização dos recursos humanos; d) características do programa desenvolvido. Para isso, foram aplicados questionários junto aos gestores das escolas privadas $(n=12)$, municipais $(n=35)$ e estaduais $(n=12)$. Verificou-se que poucas crianças e jovens são atendidas nos programas no âmbito público. As instalações das escolas privadas e municipais são melhores que as da rede estadual; destaca-se que o município utiliza os espaços cedidos pela Secretaria Municipal de Esportes e pela Comunidade. De acordo com os gestores, o professor/treinador das PEEs não ministra Educação Física Escolar na mesma escola. Os gestores das escolas privadas e do município relataram que as PEEs não têm ligação com o Projeto Político Pedagógico (PPP) da escola, o que aponta uma descrença dos gestores quanto à possibilidade educacional das PEEs. No âmbito público, pode-se pensar em estratégias para a democratização dessas práticas, com programas intersetoriais - que articulem diferentes secretarias e a participação da comunidade, de tal forma que os orçamentos possam ser otimizados e as PEEs valorizadas no contexto em que estão inseridas. Pretende-se que esse conhecimento subsidie futuras discussões sobre programas de iniciação esportiva no contexto escolar.

UnITERMOS: Organização e gestão; Esporte escolar.

\section{Introdução}

No Ensino Fundamental, o esporte pode ser desenvolvido como um dos conteúdos da educação física escolar. Porém, cresce o número de escolas que também oferecem modalidades esportivas no contraturno, denominadas "práticas esportivas escolares (PEEs)", que são atividades extracurriculares também chamadas de "turmas de treinamento esportivo" (LuCATO, 2000).

Além de potencializar a educação de crianças e jovens, quando efetivamente encontram-se ligadas à escola por meio do projeto político pedagógico, as PEEs podem promover a democratização da prática esportiva, dada a obrigatoriedade da frequência à escola, de crianças a partir dos seis anos de idade, conforme preconiza o Artigo 6º da Lei 9.394/96, que estabelece as Diretrizes e Bases da Educação Nacional (BrasiL, 1996).
Em âmbito federal, a Secretaria Nacional de Esporte Educacional desenvolve o programa "Segundo Tempo", voltado à democratização da prática esportiva. O programa estabelece que a quantidade de alunos atendidos tenha como parâmetro o número de habitantes da cidade (BRASIL, 2009).

Pesquisas realizadas em escolas estaduais revelam uma prática seletiva que visa ao alcance de resultados nas Olimpíadas Colegiais do Estado de São Paulo (SAntos, 2003; Santos \& Simōes, 2007; Soares, 2003). SARTORI (2003) avaliou o objetivo das PEEs em escolas municipais que aplicavam o programa Segundo Tempo, e verificou uma preocupação com a formação integral dos alunos. No entanto, BASSANI, TORRI e VAZ (2003) verificaram resultados diferentes em uma escola em que os alunos participavam de competições, pois as PEEs seguiam o modelo do 
alto rendimento. De acordo com LeTTNin (2005), Teixeira e Teixeira (2006) e Sigoli (2005), as PEEs desenvolvidas em escolas privadas podem fazer parte de uma estratégia de "marketing", não tendo muitas vezes relação com o projeto político pedagógico da escola e, consequentemente, com a formação de crianças e jovens.

Nestes trabalhos foram utilizados como delineamento metodológico estudos de caso ou trabalhos realizados com amostragem intencional, de tal forma que a generalização dos resultados para determinada população não pode ser realizada. Faltam dados populacionais que permitam um diagnóstico sobre como se dá a prática esportiva escolar que permitem um diagnóstico e, a partir desses dados, uma possível elaboração de políticas públicas.

De acordo com a Política Nacional de Esporte (PNE), o Brasil precisa de um processo permanente de avaliação que permita um direcionamento correto dos recursos disponíveis para o esporte, ou seja, é necessário um processo de aplicação contínua de diagnósticos que reflita o retrato do esporte no país, a cada novo momento (BrasiL, 2005). Ainda de acordo com a PNE, o esporte educacional e o esporte escolar são de competência dos governos estaduais e municipais, necessitando-se de indicadores socioesportivos sobre: instalaçóes e equipamentos disponíveis (ginásios, quadras, praças, praias, aparelhos para esporte etc.), número de praticantes, programas existentes, vocações esportivas (pelas tradiçôes), tipos de gestão e organização, recursos financeiros disponíveis, apoio da iniciativa privada (a que existe e a potencial), recursos humanos existentes, estudo sobre a população (percentuais por faixa etária), entre outros.

No presente estudo não serão levantados todos os dados citados na PNE, mas algumas perguntas serão respondidas com relação ao município de Santos, de tal forma que seja possível refletir a necessidade de uma política Municipal de Esporte, com metas de curto, médio e longo prazo, numa perspectiva de continuidade, ou seja, de uma política que não seja apenas de governo, mas de Estado, para que a mesma tenha continuidade de realização.

Desta forma, a presente pesquisa teve por objetivo analisar a opinião dos gestores quanto às condições das práticas esportivas escolares no ensino fundamental no município de Santos - SP, com relação à: a) percentual de atendimento no âmbito público; b) descrição dos recursos materiais e financeiros; c) caracterização dos recursos humanos; e d) planejamento do programa desenvolvido.

Nossa hipótese é que as condiçōes das práticas esportivas escolares sejam diferentes nas escolas municipais, estaduais e privadas, considerando que os programas desenvolvidos têm objetivos diferentes: a) no município, que tem um programa voltado a princípios educacionais (programa Segundo Tempo), a prática possivelmente é democrática; b) no estado (Turmas de Treinamento - ACDs), que objetiva as Olimpíadas Colegiais, a prática deve ser seletiva e competitiva; c) nas escolas privadas, que possivelmente utilizam o esporte como estratégia de "marketing", a prática deve ser seletiva e com fins competitivos e econômicos.

\section{Método}

O tipo de pesquisa utilizada no presente estudo foi a descritiva ("survey") e se destina a estudar o "status" de um fenômeno (Thomas \& NeLson, 2002).

\section{Amostra}

Foi realizado o levantamento da população a ser estudada mediante o contato com a Diretoria de Ensino de Santos/SP, a qual forneceu o nome das escolas e os respectivos responsáveis. O município de Santos conta com um total de 147 escolas do ensino fundamental. Por meio de contato telefônico, verificou-se que 123 destas instituiçōes ofereciam PEEs, o que corresponde a $85 \%$ do total de escolas do município.

A amostra foi composta pela totalidade de escolas estaduais e municipais que ofereciam as PEEs (municipais $\mathrm{n}=35$ e estaduais $\mathrm{n}=12$ ); em relação às escolas privadas selecionou-se por amostragem estratificada aleatória 12 escolas (equivalente a 19,4\%), levando-se em consideração as regiōes (bairros) do município de Santos (TABELA 1). 
TABELA 1 - Número de escolas e administradores (coordenadores, diretores ou responsáveis pelos programas) avaliados.

\begin{tabular}{lcccc}
\hline & \multicolumn{3}{c}{ ORIGEM DA ESCOLA } & Total \\
\cline { 2 - 5 } & PRIVADAS & MUNICIPAIS & ESTADUAIS & 61 \\
\hline Escolas & 12 & 37 & 12 & 15 \\
Administradores & 12 & 2 & 1 & \\
\hline
\end{tabular}

A coleta de dados nas escolas ocorreu por meio de aplicação de questionário com os gestores responsáveis pela implantação dos programas nas escolas. Nas escolas municipais, participaram as duas pessoas responsáveis pelo programa "Escola Total" na rede municipal santista. Nas escolas estaduais, contou-se com a colaboração da responsável pelas "atividades curriculares desportivas" ou "turmas de treinamento" (pertencente à Oficina Pedagógica da Educação Física). Nas escolas privadas, os diretores/coordenadores das 12 escolas participaram da amostra. Todos os sujeitos assinaram o termo de consentimento livre e esclarecido.

O presente estudo foi aprovado pelo Comitê de Ética da Escola de Educação Física e Esporte da Universidade de São Paulo (CEP: 2010/08) e acompanham normas da Resolução 196/96 do Conselho Nacional de Saúde sobre pesquisas envolvendo seres humanos.

\section{Procedimentos}

Foi utilizado como instrumentos de medida um questionário elaborado segundo a técnica sugerida por Thomas e Nelson (2002), com base nos estudos de Arena (2000), Lettnin (2005), TsuKamoto (2004) e UNESCO (2004). A validade de conteúdo do instrumento utilizado foi obtida através do julgamento de especialistas. Para isso, contou-se com a colaboração de três professores da Escola de Educação Física e Esporte da Universidade de São Paulo. O instrumento foi testado num estudo piloto, onde algumas questôes foram readequadas.

O questionário foi dividido em três partes com o objetivo de avaliar três dimensões:

A) Dimensão Recursos materiais e financeiros: A1) Instalações - identificar as instalaçōes existentes; A2) Modalidades oferecidas - identificar as modalidades oferecidas; A3) Recursos financeiros - existência de cobrança de taxa dos alunos.

B) Dimensão Recursos humanos: B1) Caracterização - se os professores/treinadores das práticas esportivas escolares também ministram aulas de Educação Física Escolar e, a forma de remuneração dos mesmos.
C) Dimensão Caracterizaçáo do programa desenvolvido: C1) Caracterização - idade de início de treinamento, idade de início de competições, frequência do treinamento (vezes/semana), duração do treino (minutos/dia); C2) Fundamentação teórica - se as PEE estão inseridas no projeto pedagógico da escola.

A coleta de dados se deu através de visita da pesquisadora às escolas.

\section{Análise estatística}

Foram considerados três grupos para a análise dos dados, respectivamente: redes de ensino estadual, municipal e privada.

As variáveis foram classificadas em quantitativas e qualitativas. Para as variáveis quantitativas, foram realizados os testes de normalidade e de homocedasticidade, onde apenas a idade de início do treinamento e a idade de início na competição apresentaram distribuição normal; foi aplicada Análise de Variância a um fator para verificar as possíveis diferenças entre as médias. Para as demais variáveis quantitativas, dado que não apresentaram distribuição normal, utilizou-se estatística não paramétrica, através da utilização de mediana e amplitude, e do teste de Kruskal Wallis, para verificar-se a existência de diferenças significantes estatisticamente entre as redes de ensino pesquisadas.

Para as variáveis qualitativas, foram elaboradas tabelas cruzadas da frequência de distribuição das variáveis estudadas para comparaçáo entre as três redes de ensino; foi calculado o teste Qui-quadrado, para verificar a existência de diferenças significantes entre as mesmas para cada variável considerada. $\mathrm{Na}$ análise estatística foi utilizado o programa SPSS 13.0 for Windows.

Como limitação da presente pesquisa cita-se o fato da mesma ter sido realizada junto aos gestores escolares. Contudo, não foram avaliados os programas implantados na prática (por meio de pesquisa observacional, por exemplo). A utilização de questionário como instrumento de pesquisa apresenta uma limitação quanto à veracidade da informação coletada, que não garante que as respostas dos avaliados correspondam ao que é realizado (Thomas \& Nelson, 2002). 


\section{Resultados}

Os resultados e discussão serão apresentados de acordo com os objetivos do estudo, sendo eles: a) percentual de atendimento no âmbito público; b) descrição dos recursos materiais e financeiros; c) caracterização do professor/treinador; d) caracterização dos programas desenvolvidos.

O número de alunos participantes das PEEs nas escolas públicas (dados populacionais) é baixo quando comparado ao número de matriculados, correspondendo a 9,4\% nas escolas municipais e $21,4 \%$ nas escolas estaduais.

Os recursos materiais e financeiros das três redes de ensino são apresentados nas TABELAS 2 a 4 (instalações, modalidades oferecidas e recursos financeiros).
As instalaçôes mais citadas foram: quadra poliesportiva, sala de ginástica, vestiários e ginásios (TABELA 2). As diferenças entre as origens das escolas foram observadas em relação ao número de piscinas e campos de areia ou grama; tanto as escolas privadas quanto as municipais relataram dispor de tais espaços.

As modalidades esportivas mais oferecidas são o futsal e o voleibol (TABELA 3). Com relação à origem, observou-se que as escolas privadas oferecem mais futsal (100\%), tênis de mesa (75\%), capoeira (33,3\%), handebol (50\%), tênis (16,7\%) e patinação $(16,7 \%)$, quando comparadas às escolas municipais e estaduais.

As escolas municipais e estaduais não cobram taxas dos alunos; em contrapartida, 50\% das escolas privadas cobram alguma taxa (TABELA 4).

TABELA 2 - Frequência absoluta (FA) e frequência relativa (FR) para a variável "instalações existentes nas escolas" de acordo com a origem das escolas.

\begin{tabular}{|c|c|c|c|c|c|c|}
\hline \multirow{3}{*}{$\begin{array}{l}\text { * Diferença estatistica- } \\
\text { mente significante em } \\
\text { relação à origem das } \\
\text { escolas }(p<0,05) \text {. }\end{array}$} & & & \multicolumn{3}{|c|}{ ORIGEM DA ESCOLA } & \multirow{2}{*}{ Total } \\
\hline & & & PRIVADAS & MUNICIPAIS & ESTADUAIS & \\
\hline & \multirow[t]{2}{*}{ Quadra poliesportiva } & FA & 11 & 34 & 12 & 57 \\
\hline & & FR & $91,7 \%$ & $97,1 \%$ & $100,0 \%$ & $96,6 \%$ \\
\hline & \multirow[t]{2}{*}{ Sala de ginástica ou salão } & FA & 9 & 31 & 11 & 51 \\
\hline & & FR & $75,0 \%$ & $88,6 \%$ & $91,7 \%$ & $86,4 \%$ \\
\hline & \multirow[t]{2}{*}{ Vestiários } & FA & 6 & 26 & 11 & 43 \\
\hline & & FR & $50,0 \%$ & $74,3 \%$ & $91,7 \%$ & $72,9 \%$ \\
\hline & \multirow[t]{2}{*}{ Ginásio } & FA & 6 & 12 & 1 & 19 \\
\hline & & FR & $50,0 \%$ & $34,3 \%$ & $8,3 \%$ & $32,2 \%$ \\
\hline & \multirow[t]{2}{*}{ Piscina* } & FA & 4 & 14 & 0 & 18 \\
\hline & & FR & $33,3 \%$ & $40,0 \%$ & $0,0 \%$ & $30,5 \%$ \\
\hline & \multirow[t]{2}{*}{ Campo de areia ou grama* } & FA & 1 & 15 & 0 & 16 \\
\hline & & FR & $8,3 \%$ & $42,9 \%$ & $0,0 \%$ & $27,1 \%$ \\
\hline & \multirow[t]{2}{*}{ Pátio } & FA & 0 & 4 & 0 & 4 \\
\hline & & FR & $0,0 \%$ & $11,4 \%$ & $0,0 \%$ & $6,8 \%$ \\
\hline & \multirow[t]{2}{*}{ Pista de atletismo } & FA & 1 & 0 & 0 & 1 \\
\hline & & FR & $8,3 \%$ & $0,0 \%$ & 0,0 & $1,7 \%$ \\
\hline & \multirow[t]{2}{*}{ TOTAL } & FA & 12 & 35 & 12 & 59 \\
\hline & & FR & $100 \%$ & $100 \%$ & $100 \%$ & $100 \%$ \\
\hline
\end{tabular}


TABELA 3 - Frequência absoluta (frequência relativa) da modalidades esportivas oferecidas de acordo com a origem da escola.

\begin{tabular}{|c|c|c|c|c|}
\hline & \multicolumn{3}{|c|}{ ORIGEM DA ESCOLA } & \multirow{2}{*}{ Total } \\
\hline & PRIVADAS & MUNICIPAIS & ESTADUAIS & \\
\hline Futsal* & $12(100 \%)$ & $21(60 \%)$ & $8(66,7 \%)$ & $41(69,5 \%)$ \\
\hline Voleibol & $3(25 \%)$ & $21(60 \%)$ & $8(66,7 \%)$ & $32(54,2 \%)$ \\
\hline Judô & $3(25 \%)$ & $6(17,1 \%)$ & $1(8,3 \%)$ & $10(16,9 \%)$ \\
\hline Tênis de mesa* & $9(75 \%)$ & $0(0 \%)$ & $1(8,3 \%)$ & $10(16,9 \%)$ \\
\hline Basquete & $3(25 \%)$ & $3(8,6 \%)$ & $2(16,7 \%)$ & $8(13,6 \%)$ \\
\hline Capoeira* $^{*}$ & $4(33,3 \%)$ & $4(11,4 \%)$ & $0(0 \%)$ & $8(13,6 \%)$ \\
\hline Caratê & $2(16,7 \%)$ & $6(17,1 \%)$ & $0(0 \%)$ & $8(13,6 \%)$ \\
\hline Handebol* & $6(50 \%)$ & $0(0 \%)$ & $4(33 \%)$ & $6(10,2 \%)$ \\
\hline Futebol & $1(8,3 \%)$ & $3(8,6 \%)$ & $0(0 \%)$ & $4(6,8 \%)$ \\
\hline Tênis* & $2(16,7 \%)$ & $2(5,7 \%)$ & $0(0 \%)$ & $2(3,4 \%)$ \\
\hline Patinação* & $2(16,7 \%)$ & $2(5,7 \%)$ & $0(0 \%)$ & $2(3,4 \%)$ \\
\hline Taekwondo & $1(8,3 \%)$ & $8(22,9 \%)$ & $0(0 \%)$ & $1(1,7 \%)$ \\
\hline Ginástica artística & $1(8,3 \%)$ & $0(0 \%)$ & $0(0 \%)$ & $1(1,7 \%)$ \\
\hline Bike & $1(8,3 \%)$ & $1(2,9 \%)$ & $0(0 \%)$ & $1(1,7 \%)$ \\
\hline TOTAL & $12(100 \%)$ & $35(100 \%)$ & $12(100 \%)$ & $59(100 \%)$ \\
\hline
\end{tabular}

TABELA 4 - Frequência absoluta (FA), frequência relativa (FR) e resultado do teste de Qui-quadrado para a variável "taxa mensal cobrada dos alunos".

\begin{tabular}{|c|c|c|c|c|c|c|c|}
\hline & & & \multicolumn{3}{|c|}{ ORIGEM DAS ESCOLAS ${ }^{\mathrm{a}}$} & \multirow{2}{*}{ Total } & \multirow{2}{*}{$\begin{array}{l}\text { a Qui-quadrado = 25,7; } \\
p=0,000 .\end{array}$} \\
\hline & & & PRIVADAS & MINICIPAIS & ESTADUAIS & & \\
\hline & \multirow[t]{2}{*}{$\operatorname{sim}$} & FA & 5 & 0 & 0 & 5 & \\
\hline & & FR & $50,0 \%$ & $0,0 \%$ & $0,0 \%$ & $8,8 \%$ & \\
\hline & \multirow[t]{2}{*}{ não } & FA & 5 & 35 & 12 & 52 & \\
\hline & & FR & $50,0 \%$ & $100,0 \%$ & $100,0 \%$ & $91,2 \%$ & \\
\hline \multirow[t]{2}{*}{ Total } & & FA & 10 & 35 & 12 & 57 & \\
\hline & & FR & $100,0 \%$ & $100,0 \%$ & $100,0 \%$ & $100,0 \%$ & \\
\hline
\end{tabular}

A caracterização da vinculação dos recursos humanos está apresentada nas TABELAS 5 e 6.

Os professores/treinadores das escolas municipais e estaduais não ministram aulas de educação física escolar na mesma escola que em atuam com as PEEs; metade das escolas privadas avaliadas apresenta professores/treinadores que atuam com educação física escolar na mesma escola (TABELA 5).

Nas escolas municipais, os professores/treinadores são estagiários/monitores (graduandos de curso de educação física) supervisionados por professores formados (nas áreas de educação física, pedagogia e administração). Os estagiários/monitores ministram as aulas e são remunerados com uma ajuda de custo paga pelo programa Segundo Tempo e pela Secretaria Municipal de Educação.

Os professores/treinadores de escolas estaduais recebem hora-aula dentro da carga horária de trabalho. A abertura das turmas de treinamento (nome das PEEs nas escolas estaduais) ocorre mediante a apresentação de um projeto para a diretoria de ensino e, após aprovação, as aulas vão para atribuição. Dessa forma, os professores/treinadores que abrem as turmas (elaboram os projetos) não são, necessariamente, os responsáveis por elas.

Os professores/treinadores das escolas privadas, em sua maioria, recebem hora-aula dentro da carga horária de trabalho (TABELA 6).
* Diferença estatisticamente significante em relação à origem das escolas $(p<0,05)$. 
TABELA 5 - Frequência absoluta (FA), frequência relativa (FR) e resultado do teste de Qui-quadrado para a variável "professores/treinadores das PEEs que ministram aulas de educação física escolar".

${ }^{\text {a }}$ Qui-quadrado $=81,9$; $p=0,000$.

\begin{tabular}{|c|c|c|c|c|c|}
\hline & & \multicolumn{3}{|c|}{ ORIGEM DAS ESCOLAS ${ }^{a}$} & \multirow{2}{*}{ Total } \\
\hline & & PRIVADAS & MINICIPAIS & ESTADUAIS & \\
\hline \multirow[t]{2}{*}{ não } & FA & 5 & 35 & 0 & 40 \\
\hline & FR & $50,0 \%$ & $100,0 \%$ & $0,0 \%$ & $70,2 \%$ \\
\hline \multirow[t]{2}{*}{ sim, mas não todos } & FA & 5 & 0 & 0 & 5 \\
\hline & FR & $50,0 \%$ & $0,0 \%$ & $0,0 \%$ & $8,8 \%$ \\
\hline \multirow[t]{2}{*}{ sim, mas são professores em outras escolas } & FA & 0 & 0 & 12 & 12 \\
\hline & FR & $0,0 \%$ & $0,0 \%$ & $100,0 \%$ & $21,1 \%$ \\
\hline \multirow[t]{2}{*}{ Total } & FA & 10 & 35 & 12 & 57 \\
\hline & FR & $100,0 \%$ & $100,0 \%$ & $100,0 \%$ & $100,0 \%$ \\
\hline
\end{tabular}

a Qui-quadrado $=94,9$ $p=0,000$.

TABELA 6 - Frequência absoluta (FA), frequência relativa (FR) e resultado do teste de Qui-quadrado quanto à remuneração dos professores/treinadores.

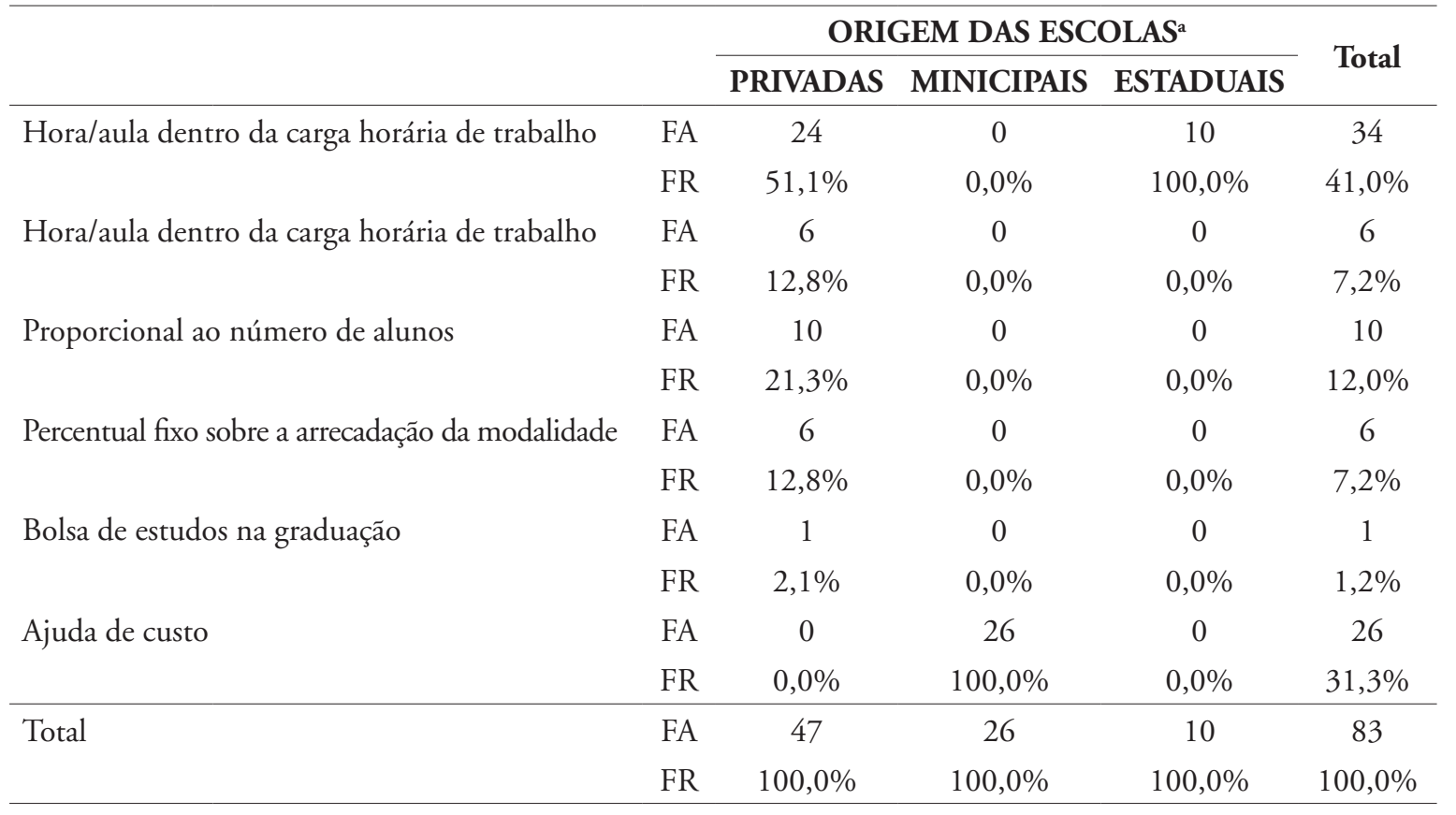

A caracterização dos programas desenvolvidos está descrita nas TABELAS 7 até 10 .

Verificou-se que as escolas privadas e estaduais participam de competições, diferentemente das escolas municipais (TABELA 7).

As escolas estaduais e municipais treinam mais vezes por semana do que as escolas privadas, de acordo com as opiniōes dos coordenadores/diretores (TABELA 8).
As escolas municipais funcionam em formato de escola geral (oferecem várias modalidades) (TABELA 9).

De acordo com os diretores/coordenadores de escolas privadas $(55,6 \%)$ e o administrador responsável pelas escolas municipais, as PEEs não estão inseridas no projeto político pedagógico (PPP) da escola (TABELA 10); o administrador das escolas estaduais acredita nessa inserção. 
TABELA 7 - Média (desvio-padrão) e resultado do teste de Anova entre os grupos estudados para as variáveis "idades de início do treinamento" e "início nas competições".

\begin{tabular}{lccccc}
\hline & \multicolumn{3}{c}{ ORIGEM DA ESCOLA } & \multirow{2}{*}{ F } & p \\
\cline { 2 - 5 } & PRIVADAS & MUNICIPAIS & ESTADUAIS & & \\
\hline Idade de início no treinamento & $6,2(2,1)$ & $6,0(0,0)$ & $11,1(0,5)$ & 146,1 & 0,000 \\
Idade de início nas competições & $8,1(2,9)$ & - & $11,1(0,5)$ & 12,5 & 0,002 \\
\hline
\end{tabular}

TABELA 8 -Mediana (amplitude) e resultado do teste de Kruskal Wallis das variáveis "número de aulas/treinos por semana" e "duração da aula/treino" na opinião dos coordenadores/diretores.

\begin{tabular}{lccc}
\hline & \multicolumn{3}{c}{ ORIGEM DA ESCOLA } \\
\cline { 2 - 4 } & PRIVADAS & MUNICIPAIS & ESTADUAIS \\
\hline Número de aulas/treinos por semana * & $2(1)$ & $6(0)$ & $3(0)$ \\
Duração da aula/treino em minutos* & $60(70)$ & $45(0)$ & $60(0)$ \\
\hline
\end{tabular}

* Diferença estatisticamente significante entre as três redes de ensino $(p<0,05)$.

Duração da aula/treino em minutos*

$60(70)$

$45(0)$

$60(0)$

TABELA 9 - Frequência absoluta (FA), frequência relativa (FR) da variável "tipo de escola oferecida - geral (onde são oferecidas várias modalidades esportivas) ou específica (é oferecida uma única modalidade)”, e o resultado do teste de Qui-quadrado.

\begin{tabular}{|c|c|c|c|c|c|c|}
\hline & & & \multicolumn{3}{|c|}{ ORIGEM DAS ESCOLAS } & \multirow{2}{*}{ Total } \\
\hline & & & PRIVADAS & MINICIPAIS & ESTADUAIS & \\
\hline & \multirow[t]{2}{*}{ escola geral } & FA & 1 & 35 & 0 & 36 \\
\hline & & FR & $11,1 \%$ & $100,0 \%$ & $0,0 \%$ & $64,3 \%$ \\
\hline & \multirow[t]{2}{*}{ escola específica } & FA & 8 & 0 & 12 & 20 \\
\hline & & FR & $88,9 \%$ & $0,0 \%$ & $100,0 \%$ & $35,7 \%$ \\
\hline \multirow{2}{*}{\multicolumn{2}{|c|}{ Total }} & FA & 9 & 35 & 12 & 56 \\
\hline & & FR & $100,0 \%$ & $100,0 \%$ & $100,0 \%$ & $100,0 \%$ \\
\hline
\end{tabular}

TABELA 10 - Frequência absoluta (FA), frequência relativa (FR) e resultado do teste de Qui-quadrado para a variável "as PEEs estão inseridas no projeto político pedagógico da escola" .

\begin{tabular}{|c|c|c|c|c|c|}
\hline & & & \multicolumn{3}{|c|}{ ORIGEM DAS ESCOLAS ${ }^{a}$} \\
\hline & & & PRIVADAS & MINICIPAIS & ESTADUAIS \\
\hline & \multirow[t]{2}{*}{$\operatorname{sim}$} & FA & 4 & 0 & 1 coordenador \\
\hline & & FR & $44,4 \%$ & $0,0 \%$ & $100,0 \%$ \\
\hline & \multirow[t]{2}{*}{ não } & FA & 5 & 1 coordenador & 0 \\
\hline & & FR & $55,6 \%$ & $100,0 \%$ & $0,0 \%$ \\
\hline \multirow{2}{*}{\multicolumn{2}{|c|}{ Total }} & FA & 9 & & \\
\hline & & FR & $100,0 \%$ & & \\
\hline
\end{tabular}




\section{Discussão}

No presente estudo, através de dados populacionais das redes públicas, observamos que o acesso às PEEs é para poucas crianças. No ensino público deveria ocorrer a democratização das PEEs, através do aumento do número de participantes, pois as mesmas podem ser consideradas parte do processo educativo.

O esporte é direito de todos, conforme a Constituição Federal, Estatuto da Criança e do Adolescente e Lei de Diretrizes e Bases da Educação Nacional (Brasil, 1988, 1990, 1996). Desta forma, sendo a escola o local que todas as crianças devem frequentar, nela, além das atividades escolares curriculares normais, outras atividades extracurriculares, artísticas e esportivas, deveriam ser desenvolvidas. Com menos de $10 \%$ de crianças e jovens atendidos, percebe-se que a universalização e o direito ao esporte ainda não ocorrem na escola. No entanto, é importante ressaltar que o direito ao esporte também pode ser garantido em outros espaços que não a escola.

Deste modo, faz-se necessária uma gestão pública efetivamente séria, com foco em políticas públicas, planos, programas, projetos e ações que traduzam, de forma ordenada, os princípios emanados da Constituição e das Leis, em estreita articulação com a sociedade.

Uma possível solução para a democratização das PEEs seria a atuação conjunta de outros setores governamentais na execução de programas integrados que garantam recursos (equipamentos, remuneração dos educadores, espaços adequados) (PACHECO, 2009). Essa perspectiva intersetorial, aconteceria através da organização e execução de projetos entre as diversas secretarias (Educação, Esportes, Turismo, Cultura, etc.).

Em atuação isolada, a Secretaria Nacional do Esporte criou o programa Segundo Tempo, cuja previsão orçamentária para o ano de 2010 é de 220 milhões de reais. Esse montante beneficiará 1,75\% da população; um número tão pequeno que nem permite que este seja considerado um programa de política pública. Em contrapartida, o Governo Federal elaborou um programa chamado "Mais Educação", que consiste em parcerias (Ministérios da Educação, do Esporte, do Desenvolvimento Social e Combate à Fome, da Cultura, da Ciência e Tecnologia, do Meio Ambiente e a Secretaria Nacional da Juventude da Presidência da República). Essas parcerias propiciarão a ampliação da jornada escolar, utilização de espaços educativos fora das escolas (centros comunitários, clubes, parques, praças, etc.), bem como a integração com a comunidade.

A vantagem de programas integrados como o "Mais Educação" é que os orçamentos podem ser otimizados. O programa Segundo Tempo, por exemplo, destina a maior parte do seu orçamento para o reforço alimentar das crianças, a cada 100 beneficiados, 13.200 reais são gastos em alimentação (BRASIL, 2009). Com o trabalho conjunto com o Ministério da Educação o custo seria reduzido, pois compete a este Ministério o financiamento da alimentação. As escolas em tempo integral também permitem a articulação de Secretarias nas esferas estadual e municipal. Contudo, na atualidade, apenas 2,79\% das escolas do estado de São Paulo funcionam nesse modelo. Cabe ressaltar que o Estado de São Paulo possui 14.293 escolas públicas, das quais 11.835 possuem quadra, ou seja, têm potencial para desenvolver esses projetos.

Para PACHECO (2009), a qualidade dos projetos de escola em tempo integral deve ser levada em consideração, mas é prioritário melhorar e qualificar o atendimento educacional na escola pública de horário parcial antes da implantação de propostas de escolas de tempo integral.

Além da intersetorialidade, os programas devem considerar a participação da comunidade. PACHECO (2009) avaliou os Centros Educacionais Unificados (CEUs) da cidade de São Paulo e concluiu que as grandes construções arquitetônicas em pouco alteraram a qualidade da escola pública municipal. $\mathrm{O}$ autor cita que não ocorreu uma discussão democrática sobre a implantação e controle dos programas desenvolvidos nestes locais.

Nas escolas estaduais a dinâmica das "turmas de treinamento" não permite que o número de atendidos aumente. De acordo com a Resolução 173, de 2002: "as unidades escolares poderão organizar até uma turma de Atividade Curricular Desportiva (ACDs) por categoria, modalidade e gênero (masculino, feminino ou misto)", de tal forma que para cada modalidade, sexo e categoria, pode ser formada apenas uma turma (SÃo PAULO, 2002). Além disso, conforme descrito por SOARES (2003), a existência das ACDs depende do interesse do diretor e de professores disponíveis e comprometidos. Isso ocorre devido às normas, que estabelecem que os professores devem preencher sua carga horária com aulas de educação física escolar e depois assumir turmas de treinamento. Nesse sentido, SoARes (2003, p.34) complementa com o discurso de um professor entrevistado: "diretores que não gostam de esporte, não abrem turma de treinamento".

Com relação ao segundo objetivo "descrição dos recursos materiais e financeiros", verificou-se 
que as escolas municipais e privadas apresentaram muitas instalações. Um fator que nos surpreendeu foi a disponibilidade de piscinas e campos de areia em escolas municipais, fruto de parcerias com a Secretaria Municipal de Esportes e a comunidade, na cessão de espaços próximos às escolas.

Nas escolas municipais, o modelo é o de escola em tempo integral que, de acordo com CAVALIERE (2009), tende a articular instituições e projetos da sociedade, não necessariamente no espaço escolar, mas, preferencialmente, fora dele. A autora cita que outra forma de oferecer o tempo integral é investindo em mudanças no interior das unidades escolares, de forma que possam oferecer condiçôes compatíveis com a presença de alunos e professores em turno integral. Três escolas municipais foram recentemente construídas para atender o contraturno dentro da própria escola.

No programa Segundo Tempo (utilizado nas escolas municipais), afirma-se que poderão ser utilizados os espaços físicos escolares ou comunitários, públicos ou privados, preferencialmente localizados próximos à comunidade beneficiada, que não demandem transporte para o deslocamento dos beneficiados (Brasil, 2009). No caso do município de Santos, o vínculo com a Prefeitura permite que esse deslocamento ocorra de ônibus, uma vez que nem sempre as instalações estão próximas às escolas.

As modalidades esportivas mais oferecidas através das PEEs são o futsal e o voleibol. Com relação à origem, observou-se que as escolas privadas oferecem mais futsal (100\%), tênis de mesa (75\%), capoeira $(33,3 \%)$, handebol $(50 \%)$, tênis $(16,7 \%)$ e patinação (16,7\%), quando comparadas às escolas municipais e estaduais.

Esses dados concordam com LETTNIN (2005), que avaliou as PEEs em escolas privadas, e observou que as modalidades de maior frequência eram o futsal (oferecido por $89 \%$ das escolas), o voleibol e o handebol (56\%). A autora observou que as escolas privadas também oferecem "taekwondo", ginástica artística, judô, ginástica rítmica desportiva, capoeira e xadrez; verificou ainda que os pais consideram que escolas de qualidade são aquelas que oferecem muitas atividades. $\mathrm{O}$ esporte, neste cenário, funciona como produto de consumo para atrair clientela com poder aquisitivo, promovendo o nome da instituição através do "marketing".

Apesar de 97\% das escolas municipais possuírem quadra poliesportiva, nenhuma delas oferece handebol, modalidade praticada no espaço escolar. Além disso, 40\% das escolas do município relataram a possibilidade de utilizar a piscina e $42,9 \%$, o campo de areia ou grama; apesar disso, apenas $8,6 \%$ oferecem futebol e nenhuma oferece natação. Cabe salientar que no programa Segundo Tempo, adotado pelo município, sugere-se a prática das modalidades futebol, natação e handebol.

As escolas estaduais relataram oferecer as quatro modalidades mais conhecidas (futsal, voleibol, handebol e basquetebol), e 8,3\% delas relataram oferecer judô e tênis de mesa.

A escolha das modalidades a serem praticadas pode seguir o princípio do regionalismo (princípio do esporte educacional). De acordo com TuBino (1996), devemos propor modalidades que respeitem, protejam e valorizem as raízes e heranças culturais, de forma a resgatar e preservar a identidade cultural. Dessa forma, a escolha deve se dar mediante as necessidades e cultura da comunidade.

Apesar de Santos ser uma cidade litorânea, com disponibilidade de grande extensão de praia, ideal para a prática de diversas modalidades esportivas aquáticas e de areia, verificou-se que nenhuma escola utiliza a praia para as PEEs.

As escolas municipais e estaduais não cobram taxas dos alunos; em contrapartida, 50\% das escolas privadas cobram alguma taxa pelas atividades desenvolvidas. No trabalho de LETTNIN (2005), todas as escolas privadas avaliadas cobravam algum valor dos alunos, e justificavam que a destinação da arrecadação era para custos de operacionalização, sendo priorizado o pagamento dos professores/treinadores. Para a autora, o esporte, na amostra avaliada, era utilizado como estratégia de "marketing" da escola para captar maior número de alunos.

No terceiro objetivo do presente estudo "caracterização dos recursos humanos", verificou-se que os professores/treinadores das escolas municipais e estaduais não ministram aulas de educação física escolar na mesma escola em que trabalham com as PEEs; metade das escolas privadas avaliadas apresenta professores/treinadores que atuam com educação física escolar na mesma escola. Acreditamos que a instituição deveria preocupar-se com o envolvimento desse profissional com o projeto político pedagógico, assim como com uma política de formação continuada para os mesmos. Segundo LETTNIN (2005), o professor contratado especificamente para ministrar PEEs pode não ter identificação com a filosofia do projeto pedagógico da escola. Geralmente, aqueles que possuem carteira assinada encontram-se presentes em todas as atividades da escola; já aqueles que possuem um contrato de prestação de serviços parecem estar desconectados do contexto comum da mesma. 
Por outro lado, o professor/treinador que ministra aulas de educação física escolar pode auxiliar no conhecimento do projeto político pedagógico da instituição. A influência do professor que possui acesso às disciplinas curriculares é maior, facilitando o envolvimento das crianças nas atividades ofertadas, diferente daquele que frequenta a escola somente em horário extracurricular. A concentração das duas atividades (professor de educação física escolar e professor/treinador de PEEs) aumenta o seu envolvimento com a escola, incentivando-o a permanecer por maior tempo na unidade, já que suas atividades profissionais estarão concentradas em um mesmo local de trabalho (LeTtNin, 2005).

Em pesquisa realizada pela UNESCO (2004), com professores de todo território nacional, cujo objetivo era o de analisar as mudanças que poderiam ocorrer no trabalho docente, verificou-se que os professores desejavam aumentar o tempo e as possibilidades de trabalho em equipe com outros colegas, tanto em sala de aula como fora dela $(87,6 \%)$, assim como concentrar sua carga horária de trabalho em apenas um estabelecimento de ensino (86,7\%).

A remuneração dos professores/treinadores é estatisticamente diferente nas redes de ensino avaliadas (municipais, estaduais e privadas). Nas escolas municipais os professores/treinadores são estagiários/ monitores e recebem ajuda de custo; nas escolas estaduais e privadas na maioria da vezes recebem hora-aula dentro da carga horária de trabalho. De maneira diferente, LETTNIN (2005) verificou em escolas privadas, que poucas assumem a responsabilidade da remuneração de seus professores; na pesquisa realizada por aquela autora, apenas uma escola da amostra assinava a carteira de trabalho para todos os professores das PEEs. Foi verificado ainda $44 \%$ de contradição nas respostas: três diretores definiam os professores como celetistas (com contratos regulares regidos pela Consolidação das Leis Trabalhistas - CLT), com "carteira assinada", e os coordenadores das mesmas escolas revelaram que alguns professores eram contratados regularmente pela CLT e outros por prestação de serviço.

A UNESCO (2004) avaliou professores de todo o Brasil e verificou que mais da metade do corpo docente do ensino público são concursados $(66,1 \%)$, existindo 9,2\% de professores efetivos sem concurso, e 19,1\% com contratos temporários. Segundo a entidade, a acelerada expansão do ensino para as crianças e jovens não se fez acompanhar pelo aumento de concursos para os professores. Os contratos temporários são realizados com professores mais jovens, ressaltando o caráter provisório e precário desse vínculo profissional.
Quanto ao último objetivo "caracterização dos programas desenvolvidos", verificou-se que as escolas privadas e estaduais participam de competiçôes, diferentemente das escolas municipais. Para Lovisolo (2001), a competição deve estar presente na escola, no entanto, deveríamos pensar num modelo que atendesse a uma proposta educacional. A competição não deve ser o principal objetivo da prática esportiva, mas deve acontecer, pois é inerente ao esporte, e deve estar articulada com o projeto pedagógico da escola. Exemplificando, SARTORI (2003) avaliou o impacto de um programa de PEEs e verificou que dentre as atividades que instigaram a disposição para a aderência dos alunos, estavam os festivais de jogos no local e a participação dos pais. Um aspecto de destaque nesta pesquisa foi o engajamento dos pais a partir dos primeiros festivais de jogos.

As escolas estaduais e municipais treinam mais vezes por semana (seis e três vezes, respectivamente) comparado com as escolas privadas (duas vezes por semana). Quanto ao tipo de atividades desenvolvidas, as escolas municipais oferecem modalidades em formato de escolas gerais, oferecendo diversas modalidades esportivas para uma mesma turma; já as estaduais e particulares funcionam em formato de escola específica (oferecem uma única modalidade). De acordo com a literatura, na fase de iniciação esportiva devem ser asseguradas a preparação multilateral e a formação geral das crianças e dos jovens (Barbanti, 2005; BOMPA, 2002; Filin, 1996; WeINECK, 1999). Neste sentido, devem ser desenvolvidas preferencialmente atividades esportivas através das escolas de esportes gerais, nas quais são praticadas diferentes modalidades (BERMÚDEZ \& Chaurra, 2003; Tsukamoto \& NunOmura, 2005).

Nas escolas municipais as PEEs não estão inseridas no projeto político pedagógico da escola, conforme destacado pela coordenadora entrevistada: Não está ligada ao projeto político pedagógico, infelizmente. A cidade de Santos, com 1500 alunos, não tem espaço adequado. Nem o pátio pode ser utilizado (está sendo servida a merenda). O contraturno ele sai, ele vai para os espaços adequados. A gente está tentando cada vez mais aproximar, tentando com que a escola reconheça que o que ele faz no contraturno contribui significativamente na formação dele.

O mesmo acontece com as escolas privadas, que de acordo com seus diretores/coordenadores (55,6\%), não vinculam as PEEs com o PPP. Já na rede estadual, segundo o gestor responsável, existe ligação das PEEs com o PPP da rede. 
É importante destacar que o programa Segundo Tempo, implantado nas escolas do Município, estabelece parcerias não somente com escolas, mas também com instituiçōes públicas em geral, e entidades privadas sem fins lucrativos (fundaçōes, organizaçôes da sociedade civil de interesse público - OSCIPs) (BRASIL, 2009). Desta forma, não é estabelecida a obrigatoriedade da ligação com o PPP da escola. Contudo, três das escolas avaliadas no município foram construídas para atender o contraturno na própria escola, e a coordenadora relatou, ainda assim, não haver a ligação com o PPP.

Nas escolas estaduais, o esporte está ligado ao PPP, conforme descrito na Resolução 173 de 5-122002, que afirma: "As Atividades Curriculares Desportivas destinadas à prática das diferentes modalidades de desporto se constituem em parte integrante da proposta pedagógica da escola”. Tal documento, expedido pela Secretaria de Educação do Estado de São Paulo, estabelece parâmetros para a abertura das turmas de treinamento (ACDs) (SÃO Paulo, 2002).

\section{Conclusão}

Apesar do potencial das PEEs em contribuir para a formação da cidadania e democratização da prática esportiva, verificou-se que na cidade de Santos - SP tal fato não vem ocorrendo, já que os programas atendem a poucos e parecem distantes do PPP das escolas.

Muitas escolas de Santos oferecem PEEs, contudo, poucas crianças são atendidas nos programas no âmbito público, fazendo-se necessária uma gestão pública com foco em políticas públicas que traduzam, de forma ordenada, os princípios emanados da Constituiçãao e das Leis, em estreita articulação com a sociedade. Sugerem-se estratégias para a democratização dessas práticas, através de programas intersetoriais - que articulem diferentes secretarias (Esporte, Cultura, Educação, entre outras) e a participação da comunidade, de tal forma que os orçamentos possam ser otimizados, e as PEEs valorizadas no contexto em que estão inseridas.

As instalaçôes das escolas privadas e municipais são melhores do que as estaduais; destaca-se que o município utiliza de espaços cedidos pela Secretaria Municipal de Esportes e da comunidade, já que o programa é o de escola em tempo integral que tende a articular instituições e projetos da sociedade, possivelmente maximizando o atendimento. As escolas privadas oferecem mais modalidades do que as escolas
O PPP deve ser um documento que revele a filosofia e a forma de organização pedagógica e curricular, e traduza as intençōes e relaçōes estabelecidas entre todas as atividades desenvolvidas no ambiente educativo, contemplando não só os conteúdos curriculares, mas todas as intençōes educativas (LiBÂNEO, 2004).

LetTnin (2005) avaliou escolas privadas de Pelotas (RS) e observou que em $44 \%$ das escolas pesquisadas as PEEs estão acontecendo com pouco controle e desprendidas do PPP. A autora avaliou separadamente o diretor e o coordenador de esportes, verificando que $56 \%$ dos diretores e $78 \%$ dos coordenadores de esporte acreditam que as PEEs estão inseridas no PPP.

No entanto, VAGO (1996) e BRACHT (2000) denominam o esporte apresentado na escola sem vínculo com sua proposta pedagógica de "esporte na escola”. Para esses autores, utiliza-se o espaço da escola para a prática de modalidades esportivas, sem função pedagógica.

públicas; o município não aproveita espaços como piscinas e campo de areia ou grama para desenvolver outras modalidades e as escolas estaduais oferecem poucas modalidades; nenhuma escola avaliada relatou utilizar a praia para o oferecimento das PEEs. Uma possível interpretação para esses resultados é que apesar dos programas disporem de instalações satisfatórias, falta iniciativas para o oferecimento de outras modalidades esportivas, preferencialmente as que são relevantes socialmente (princípio do regionalismo).

As escolas municipais utilizam graduandos em Educação Física para ministrar as aulas; nas escolas estaduais os professores/treinadores concursados são os responsáveis; no entanto, eles elaboram os projetos de PEEs e as aulas vão para atribuição, de tal forma que dificilmente eles ministram PEEs no mesmo local em que lecionam educação física escolar. Metade das escolas privadas possui professores de PEEs que ministram educação física escolar na mesma escola. O fato do professor/treinador ministrar aulas de educação física escolar na escola pode auxiliar no conhecimento do projeto político pedagógico da instituição e facilitar políticas de formação continuada.

As PEEs nas escolas municipais são desenvolvidas como escolas de esporte gerais, ou seja, a criança pratica várias modalidades, diferentemente das escolas estaduais 
e das privadas, entre duas e três vezes por semana com uma única modalidade. No ensino fundamental a organização do esporte em formato de escolas gerais concorda com a literatura, já que potencializa a diversificação/variabilidade motora aos alunos.

Os gestores das escolas privadas e municipais relataram que as PEEs não têm ligação com o Projeto Político Pedagógico (PPP) da escola, o que aponta uma descrença dos gestores quanto à possibilidade educacional das PEEs. A partir dos resultados pode-se supor que o esporte apresentado na maioria das escolas não tem vínculo com a escola, sendo considerado "esporte na escola", que se utiliza o espaço da escola para a prática de modalidades esportivas, sem função pedagógica.

Esperamos que o presente estudo possa subsidiar futuras discussões sobre programas de formação esportiva extracurriculares no contexto escolar.

\begin{abstract}
Administration of the schools in the city of Santos - SP

The current research aimed to analyze the conditions of the schools sports practices (SPS) in the elementary schools in the city of Santos - SP, from the perspective of the manager, in relation to: a) percentage of attendance in the public sphere; b) description of the material and financial resources; c) characterization of the human resources; d) characteristics of the human resources; $d$ ) characteristics of the program developed. To achieve this purpose, some questionnaires were filled in by managers of the private schools $(n=12)$, municipals $(n=$ 35 ) and state schools $(n=12)$. It was verified that few children and teenagers attended the programs in the public sphere. The installations in the private and city schools are better than the ones from the net of the state schools; it is stressed that the Municipalities uses the spaces assigned by the Municipal Secretariat of Sport and by the community. In accordance with the managers, the SPS teacher/coach does not teach Physical Education of School in the same school. The managers of Municipal and private schools reported that the SPS are not related to the Pedagogical Political Project (PPP) of the school, what indicates incredulity of the managers in relation to the educational SPS feasibility. In the public sphere, it is possible to think about strategies for the democratization of these practices, with inter-sector programs - that articulate different secretariats and the participation of the community, in a way that the budgets may be optimized and the PPP valued within the context in which they are included. It is expected that this knowledge subsidies future discussions about initiation sports programs within the school sphere.
\end{abstract}

UNITERMS: Organization \& administration; School sport.

\title{
Referências
}

ARENA, S.S. Iniciação e especialização esportiva na grande São Paulo. 2000. 105f. Dissertação (Mestrado) - Escola de Educação Física e Esporte, Universidade de São Paulo, São Paulo, 2000.

BARBANTI, V.J. Formação de esportistas. Barueri: Manole, 2005.

BASSANI, J.J.; TORRI, D.; VAZ, A.F. Sobre a presença do esporte na escola: paradoxos e ambigüidades. Movimento, Porto Alegre, v.9, n.2, p.89-112, 2003.

BERMÚDEZ, S.R.; CHAURRA, J.T. Orientações para a planificação do treino com crianças. Treino Desportivo, Lisboa, n.21, p.39-45, 2003.

BOMPA, T.O. Treinamento total para jovens campóes. Barueri: Manole, 2002.

BRACHT, V. Esporte na escola e esporte de rendimento. Movimento, Porto Alegre, v.12, n.6, p.14-24, 2000.

BRASIL. Constituição da República Federativa do Brasil. Brasília: Senado, 1988.

Estatuto da criança e do adolescente. Brasília: Senado, 1990.

Lei no 9.394, 20 de dezembro de 1996. Estabelece as diretrizes e bases da educação nacional. Disponível em: <http://www.planalto.gov.br/ccivil_03/Leis/L9394.htm>. Acesso em: 25 jun. 2008.

248 • Rev. bras. Educ. Fís. Esporte, São Paulo, v.25, n.2, p.237-49, abr./jun. 2011 
Ministério do Esporte. Política nacional de esporte. Brasília: ME, 2005. p.49-77. Disponível em: <http://www. esporte.gov.br>. Acesso em: 3 nov. 2009.

. Ministério do Esporte. Secretaria Nacional de Esporte Educacional. Diretrizes e orientaçóes para estabelecimento de parcerias do segundo tempo. Disponível em: <http://portal.esporte.gov.br/snee/segundotempo/default.jsp.> Acesso em: 18 nov. 2009.

CAVALIERE, A.M. Escolas de tempo integral versus alunos em tempo integral. Em Aberto, Brasília, v.22, n.80, p.51-63, 2009. FILIN, V.P. Desporto juvenil: teoria e metodologia. Londrina: Centro de Informações Desportivas, 1996.

LETTNIN, C.C. Esporte escolar: razão e finalidades. 2005. 154 f. Dissertação (Mestrado) - Universidade Federal de Santa Catarina, Santa Catarina, 2005.

LIBÂNEO, J.C. Organização e gestão da escola: teoria e prática. 5.ed. Goiânia: Alternativa, 2004.

LOVISOLO, H. Mediação: esporte rendimento e esporte da escola. Movimento, Porto Alegre, v.7, n.15, p.107-17, 2001.

LUCATO, S. Iniciação e prática escolar esportiva e suas dimensões sócio-culturais na percepção dos pais. 2000. 79 f. Dissertação (Mestrado) - Escola de Educação Física e Esporte, Universidade de São Paulo, São Paulo, 2000.

PACHECO, R.T.B. O espetáculo da educação: os Centros Educacionais Unificados do Município de São Paulo como espaços públicos de lazer. Tese (Doutorado) - Faculdade de Educação, Universidade de São Paulo, São Paulo, 2009.

SANTOS, A.L.; SIMÕES, A.C. A influência da participação de alunos em práticas esportivas escolares na percepção do clima ambiental da escola. Revista Portuguesa de Ciência do Desporto, Porto, v.7, n.1, p.26-35, 2007.

SANTOS, A.L.P. A influência da participação de alunos em práticas esportivas escolares na percepção do clima ambiental da escola. 2003. 82 f. Dissertação (Mestrado) - Escola de Educação Física e Esporte, Universidade de São Paulo, São Paulo, 2003. SÃO PAULO (Estado). Secretaria da Educação. Resolução n.173, de 5 de dezembro de 2002. Dispõe sobre as sessões de atividades curriculares desportivas nas Unidades Escolares da Rede Pública Estadual. Disponível em: <http://www. educacao.sp.gov.br/>. Acesso em: 14 set. 2009

SARTORI, R.F. Projeto esporte escolar e o impacto no desenvolvimento de seus participantes em uma comunidade de São José (SC). 2003. Dissertação (Mestrado) - Universidade Federal de Santa Catarina, Santa Catarina, 2003.

SIGOLI, M.A. O esporte educacional e a prática esportiva nas escolas da cidade de São Paulo. 2005. 62 f. Dissertação (Mestrado) - Escola de Educação Física e Esporte, Universidade de São Paulo, São Paulo, 2005.

SOARES, L.M.A. Esporte escolar: concepções e práticas. 2003. 133 f. Dissertação (Mestrado) - Escola de Educação Física e Esporte, Universidade de São Paulo, São Paulo, 2003.

TEIXEIRA, D.; TEIXEIRA, R.T.S. O mundo-vida da criança na prática do esporte escolar. Lecturas: Educacíon Fisica y Deportes, Buenos Aires, v.11, n.99, 2006.

THOMAS, J.; NELSON, J. Métodos de pesquisa em atividade física. Porto Alegre: Artmed, 2002.

TSUKAMOTO, M.H.C. A ginástica olímpica no contexto da iniciação esportiva. 2004. Dissertação (Mestrado) Escola de Educação Física e Esporte, Universidade de São Paulo, São Paulo, 2004.

TSUKAMOTO, M.H.C.; NUNOMURA, M. Iniciação esportiva e infância: um olhar sobre a ginástica artística. Revista Brasileira de Ciências do Esporte, Campinas, v.26, n.3, p.159-76, 2005.

TUBINO, M.J.G. O esporte educacional como uma dimensão social do fenômeno esportivo no Brasil. In: CONFERÊNCIA BRASILEIRA DE ESPORTE EDUCACIONAL. Memórias: conferência brasileira de esporte educacional. Rio de Janeiro: Universidade Gama Filho, 1996.

UNESCO. O perfil dos professores brasileiros: o que fazem, o que pensam, o que almejam. São Paulo: Moderna, 2004. VAGO, T.M. O "esporte na escola" e o "esporte da escola": da negação radical para uma relação de tensão permanente: um diálogo com Valter Bracht. Movimento, Porto Alegre, v.3, n.5, p.4-17, 1996.

WEINECK, J. Treinamento ideal. Barueri: Manole, 1999.

ENDEREÇO

Carla Nascimento Luguetti

Escola de Educação Fisica e Esporte - USP

Av. Prof. Mello Moraes, 65

05508-030 - São Paulo - SP - BRASIL

e-mail: luguetti@usp.br
Recebido para publicação: 12/04/2010

Revisado: 16/11/2010

Aceito: 21/03/2011 